\title{
Metformin Rescues the MG63 Osteoblasts against the Effect of High Glucose on Proliferation
}

\author{
Xinyu Shao, ${ }^{1}$ Xiaojun Cao, ${ }^{2}$ Ge Song, ${ }^{1}$ Yuan Zhao, ${ }^{1}$ and Bimin Shi ${ }^{1}$ \\ ${ }^{1}$ Department of Endocrinology and Metabolism, The First Affiliated Hospital of Soochow University, 188 Shizi Street, \\ Suzhou, Jiangsu 215006, China \\ ${ }^{2}$ Department of Endocrinology and Metabolism, Zhangjiagang First People’s Hospital, Zhangjiagang, Jiangsu 215600, China
}

Correspondence should be addressed to Bimin Shi; shibimin@163.com

Received 31 December 2013; Revised 2 March 2014; Accepted 26 March 2014; Published 9 April 2014

Academic Editor: Wang Chen

Copyright (C) 2014 Xinyu Shao et al. This is an open access article distributed under the Creative Commons Attribution License, which permits unrestricted use, distribution, and reproduction in any medium, provided the original work is properly cited.

\begin{abstract}
Aims. To study the proliferation of osteoblasts and genes expression under normal glucose, high glucose, and metformin (Met). Methods. MG63 osteoblast-like cells were cultured in osteogenic medium supplemented with normal glucose (glucose $5.5 \mathrm{mmol} / \mathrm{L}$ ) or high glucose (glucose $16.7 \mathrm{mmol} / \mathrm{L}$ ) and metformin + high glucose (Met $300 \mu \mathrm{mol} / \mathrm{L}+$ glucose $16.7 \mathrm{mmol} / \mathrm{L}$ ). Proliferation was detected with CCK-8 assay at days 1,3, and 7. Real-time PCR and Western blot were performed to compare the expression of collagen I (Col I), osteocalcin (OCN), osteoprotegerin (OPG), receptor activator for NF- $\kappa$ B ligand (RANKL), and metal matrix proteinases 1 and 2 (MMP1, MMP2). Alkaline phosphatase (ALP) activity was also detected at days 6, 12, and 18. Results. Exposure to high glucose inhibited the proliferation of osteoblasts $(P<0.05)$, with suppressed OCN and OPG. Meanwhile, Col I, RANKL, MMP1, and MMP2 were unaffected. Metformin attenuated the suppression on proliferation with increased expression of Col I, OCN, and OPG, meanwhile suppressing MMP1 and MMP2. High glucose lowered the intracellular ALP, while metformin raised it. Metformin attenuated the downregulation of ALP completely at day 6, partly at day 12, but not at day 18. Conclusions. Metformin attenuated the suppression effect of high glucose to the osteoblast proliferation and gene expression, more prominently in earlier stage.
\end{abstract}

\section{Introduction}

Hyperglycemia is one of the main causes of osteoporosis, considering the huge population of diabetes mellitus $(\mathrm{DM})$ in the world [1]. According to surveys around the world, both type 1 and type 2 diabetic patients had higher prevalence of osteopenia or osteoporosis $[2,3]$. Logically, correction of hyperglycemia became one of the most reasonable approaches people can find to improve the bone mass. Among the diversified oral hypoglycemic agents (OHA) for type 2 diabetic patients, metformin was defined as the firstchoice according to the ADA/EASD guidelines [4]. Recently, metformin was also found to be protective to the bone loss, with an increased bone density in diabetic animals [5]. But the subtle mechanisms of this protection, whether independent of the blood glucose control, and the detailed changes in the osteoblast differentiation and maturation are still to be elucidated. Some osteogenic genes were proved to be related to osteoblast differentiation, for example, collagen 1 alpha $(\mathrm{Col} \alpha)$, osteocalcin $(\mathrm{OCN})$, alkaline phosphatase (ALP), osteoprotegerin (OPG), and receptor activator for NF- $\kappa \mathrm{B}$ ligand (RANKL) [6-9]. Besides, matrix metalloproteinases (MMPs), a series of zinc-dependent endopeptidases being capable of degrading most extracellular matrix proteins, are also reported to be related to the differentiation of osteoblast [10]. How metformin affects osteoblasts is undetermined. In the present study we explored how high glucose and metformin treatment influence the proliferation and related gene expression.

\section{Materials and Methods}

Metformin, ascorbic acid, and dexamethasone were purchased from Sigma (USA). CCK-8 proliferation assay kit was from Dojindo Bio Co., Kumamoto, Japan. TRIzol nucleotide extraction kit was from Invitrogen, NY, USA. Protein 
quantification kit with BCA standard was from Nanjing Jiancheng Biology Corp., Nanjing, China. RT-PCR kit was from TaKaRa, Tokyo, Japan. MG63 osteoblastic cell line was kindly donated by Professor Qin SHI, Bone Research Lab, the First Affiliated Hospital of Soochow University.

2.1. Cell Culture. Human osteoblast-like cells MG63 were cultured in DMEM medium, supplemented with $10 \%$ fetal calf serum, $100 \mathrm{U} / \mathrm{mL}$ penicillin, and $100 \mu \mathrm{g} / \mathrm{mL}$ streptomycin at $37^{\circ} \mathrm{C}$ in $95 \%$ humidified air with $5 \% \mathrm{CO}_{2}$. The medium was replaced every 3 days, and confluent cells were digested with $0.25 \%$ trypsin and split at a rate of $1: 2-1: 3$.

MG63 cells were grouped into four: control (Ctrl, original DMEM medium), normal glucose group (NG, $5.5 \mathrm{mmol} / \mathrm{L}$ glucose), high glucose group (HG, $16.7 \mathrm{mmol} / \mathrm{L}$ glucose), and metformin treatment group ( $\mathrm{HG}+$ Met, $16.7 \mathrm{mmol} / \mathrm{L}$ glucose plus $300 \mu \mathrm{mol} / \mathrm{L}$ metformin).

2.2. Proliferation Analysis. Cell proliferation was analyzed using Cell Counting Kit-8 (CCK-8) assays. MG63 human osteoblast-like cells were plated in 96 -well plates $\left(1 \times 10^{3}\right.$ cells/well). Cells were then incubated at $37^{\circ} \mathrm{C}$ for the next 7 days with ctrl, NG, HG, and $\mathrm{HG}+$ Met mediums. At day 1 , day 3, and day 7 after seeding of the cells, CCK8 assay was performed according to the manufacturer's instructions. The optical density (OD) for each well was measured at $450 \mathrm{~nm}$ using a 96-well plate reader. Three replicate wells were used for each analysis and at least three independent experiments were performed. The cell proliferation rate was calculated according to the following equation provided by the manufacturer: the cell proliferation rate $=[(\mathrm{OD}$ experiment $-\mathrm{OD}$ blank $) /($ OD control - OD blank $)] \times 100 \%$ [11].

2.3. Quantitative RT-PCR of Osteoblast Related Genes. Primers were manufactured as Table 1 by Shanghai Sango Inc. (China). MG63 cells of four different treatments were induced with osteogenic medium $(50 \mathrm{mg} / \mathrm{L}$ ascorbic acid, $10 \mathrm{mmol} / \mathrm{L} \beta$-glycerol phosphate disodium, and $100 \mathrm{nmol} / \mathrm{L}$ dexamethasone). Cells were harvested at day 3 and day 7 , and total RNA was extracted with TRIzol method according to the protocols recommended by the manufacturer. The total RNA concentration and quantity were assessed by absorbance at $260 \mathrm{~nm}$. $\beta$-actin was designed as inner control of RT-PCR. Products were analyzed using real-time quantitative PCR and TaqMan probes. Real-time PCR was done in triplicate using the Applied Biosystems 7500 (NJ, USA).

2.4. Protein Extraction and Western Blot. MG63 osteoblasts were harvested and rinsed with cold PBS. Cells were lysed and homogenized. Then the lyastes were spined at $14000 \mathrm{rpm}$ for $10 \mathrm{~min}$ at $4^{\circ} \mathrm{C}$. Protein concentration of total protein extracted was determined by the BCA Protein Assay (Pierce Chemicals Co., Rockford, IL, USA). The protein was separated by SDS-polyacrylamide gel electrophoresis and transferred to PVDF membrane (Millipore, MA, USA) using a semidry transfer apparatus. Membrane was probed with anti-MMP1, anti-MMP2, anti-RANKL, anti-OPG (Bioworld, GA, USA), anticollagen I, anti-OCN antibody (Abcam, MA, USA), and

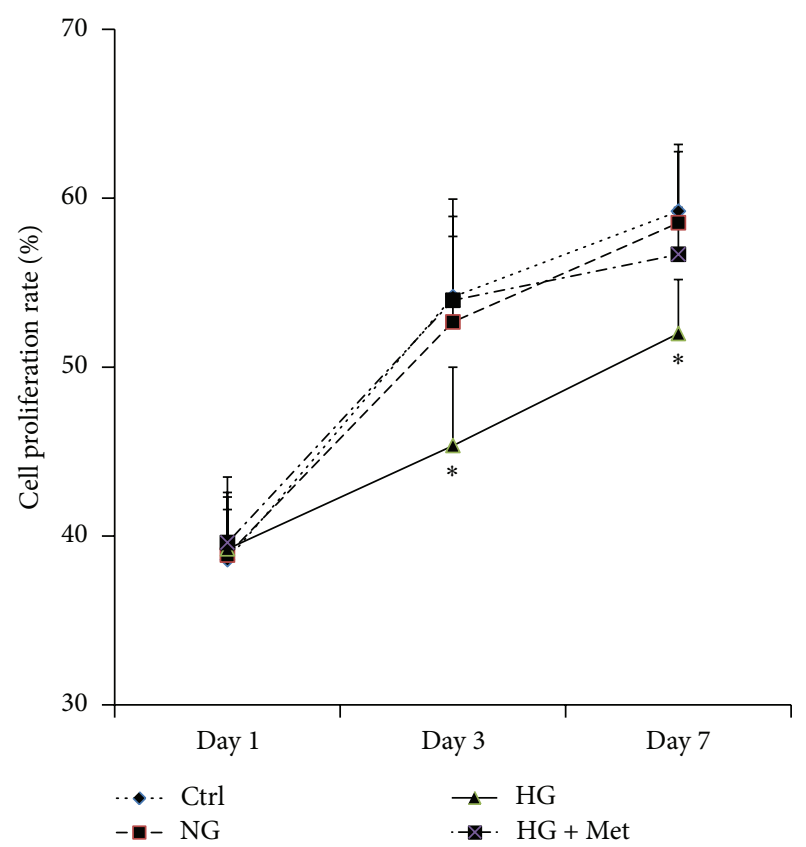

FIgURE 1: Treatment with high glucose significantly inhibited the proliferation of MG63 cells. And metformin could rescue this effect. Cell proliferation was tested by CCK8 assay as described in the methods at day 1 , day 3 , and day 7. Data represent mean \pm SD of three separate experiments. Comparison among normal glucose (NG), high glucose $(\mathrm{HG})$, and metformin treatment plus high glucose (HG + Met), ${ }^{*} P<0.05$ HG versus ctrl, NG, HG + Met.

anti-GAPDH inner control antibody (Sigma, MO, USA). And then the blots were incubated with horseradish peroxidaseconjugated secondary antibodies at room temperature for $1 \mathrm{~h}$. The immune complexes were visualized with a chemiluminescence detection system (Amersham Bioscience, NJ, USA).

2.5. Determination of Alkaline Phosphatase (ALP). Cells were plated in 6 -well plates $\left(1 \times 10^{5}\right.$ cells/well $)$. Four groups as described above were induced with osteogenic medium mentioned above. Cells were harvested and lysed at days 6, 12 , and 18. Supernatant was collected after centrifuge at $2000 \mathrm{r} / \mathrm{min}$ for $5 \mathrm{~min}$. Intracellular ALP activity was measured with automatic biochemical analyzer, with BCA adjusting for the intracellular protein content.

2.6. Statistics. All the numeric parameters were recorded as mean \pm standard deviation. The Statistical Package for Social Sciences (SPSS) 10.0 software was used for ANOVA. A $P$ value $<0.05$ was considered statistically significant.

\section{Results}

(1) To assess the influence of normal or high glucose level and metformin exposure on cell proliferation of osteoblasts, MG63 cells were cultured in conditions described above, and CCK- 8 assay was performed at day 1 , day 3, and day 7. As shown in Figure 1, CCK-8 assay was done on MG63 osteoblast-like cells cultured 
MMP1

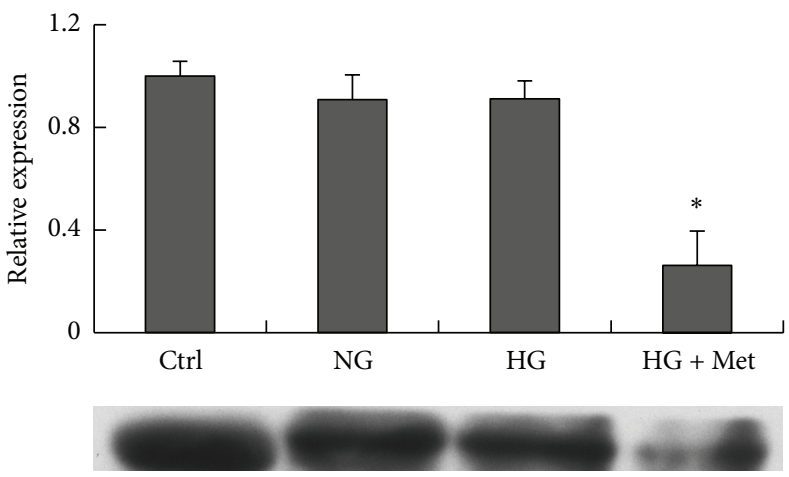

(a)

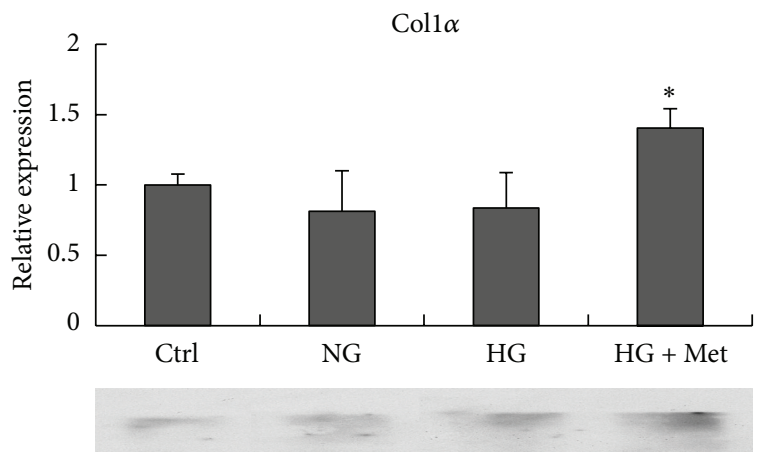

(c)

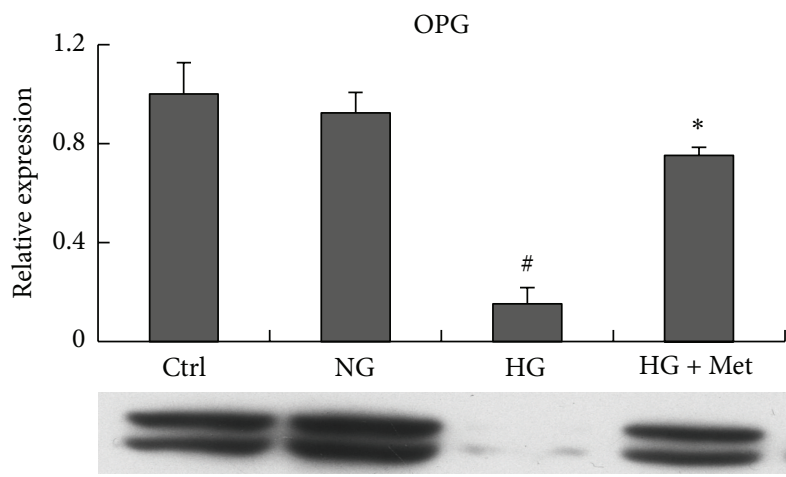

(e)

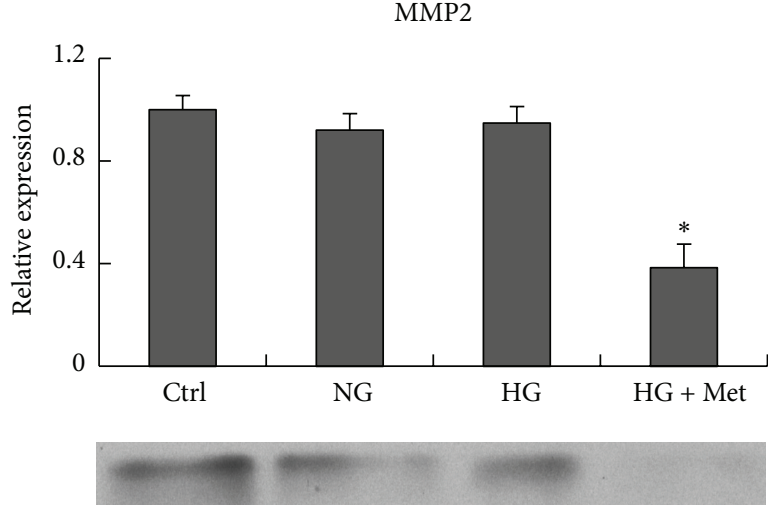

(b)

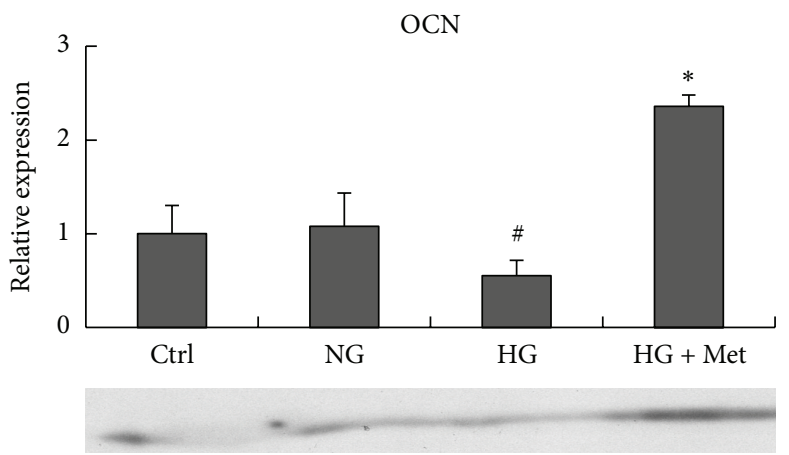

(d)

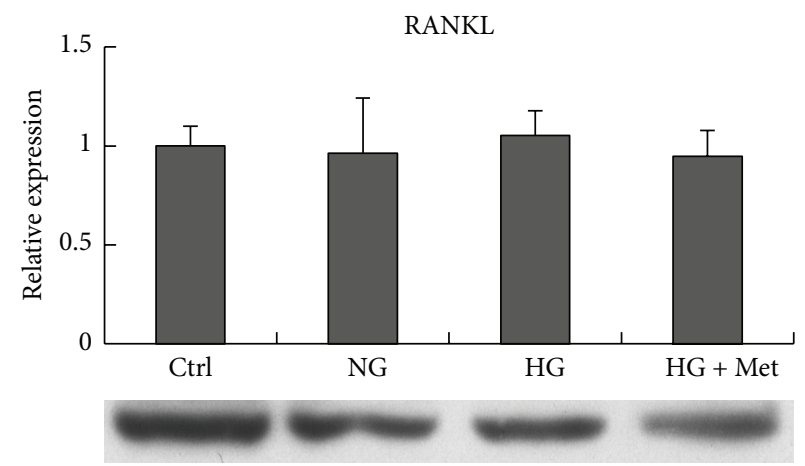

(f)

Figure 2: Results of real-time PCR and Western blot. MMP1 (a), MMP2 (b), Coll $\alpha$ (c), OCN (d), OPG (e), RANKL (f) mRNA expression and protein of MG63 cells under control DMEM (ctrl), normal glucose (NG), high glucose (HG), and metformin treatment + high glucose (HG + Met). ${ }^{*} P<0.05, \mathrm{HG}+$ Met versus ctrl, NG $(5.5 \mathrm{mmol} / \mathrm{L})$, and HG $(16.7 \mathrm{mmol} / \mathrm{L}) ;{ }^{* *} P<0.05, \mathrm{HG}+\mathrm{Met}$ versus with $\mathrm{HG}(16.7 \mathrm{mmol} / \mathrm{L})$; ${ }^{\#} P<0.05$, HG $(16.7 \mathrm{mmol} / \mathrm{L})$ versus ctrl and NG $(5.5 \mathrm{mmol} / \mathrm{L})$.

with osteogenic induction mediums supplemented with different concentrations of glucose. At day 1 , all the CCK- 8 values and proliferation were similar. After 3 and 7 days of exposure of glucose with or without metformin, MG63 cells cultured with high glucose (Glu $16.7 \mathrm{mmol} / \mathrm{L}$ ) had the lower proliferation than those with normal glucose. Metformin seemed to rescue the suppression of proliferation resulting from high glucose, both at day 3 and day 7 .
(2) To quantify the expression of osteogenesis-related genes, real-time PCR and Western blot were performed with the MG63 cells osteoblast-like cells cultured in osteogenic mediums supplemented with different concentrations of glucose, and metformin $(300 \mu \mathrm{mol} / \mathrm{L})$ was also added to high glucose medium $(16.7 \mathrm{mmol} / \mathrm{L})$. Figure 2 showed the real-time PCR and Western blot results of MG63 osteoblast-like cells cultured in different conditions mentioned 
TABle 1: Primers used in the PCR.

\begin{tabular}{lcc}
\hline Gene & Sense $\left(5^{\prime}-3^{\prime}\right)$ & Antisense $\left(5^{\prime}-3^{\prime}\right)$ \\
\hline Col I & TGTTCAGCTTTGTGGACCTC & CTTGGTCTCGTCACAGATCA \\
OCN & ATGAGAGCCCTCACACTCCTC & CTAGACCGGGCCGTAGAAGCG \\
OPG & AGTG GGAG CAGA AGAC ATTG & ATTG GACC TGGT TACC TATC \\
RANKL & GCGT CGCC CTGT TCTT CTAT & TTGG TGCT TCCT CCTT TCAT \\
MMP-1 & CTCGCTGGGAGCAAACACTG & TGATGTCTGCTTGACCCTCAGAG \\
MMP-2 & GAATGAATACTGGATCTACTCA & TTGTCTCCAGCAAAGATGTATGTC \\
\hline
\end{tabular}

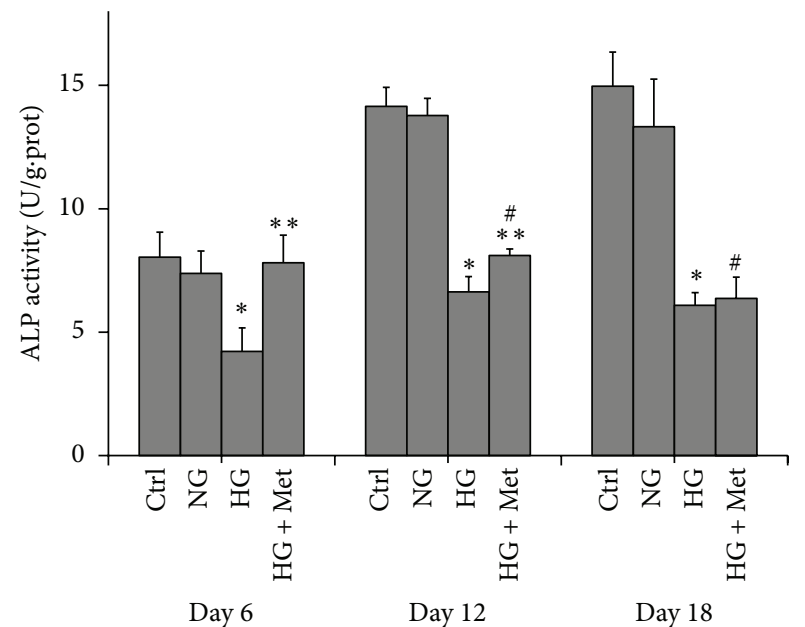

FIGURE 3: ALP activity (unit/gram of protein) of MG63 cells at days 6,12 , and 18 exposed to normal glucose (NG), high glucose (HG), and metformin $(300 \mu \mathrm{mol} / \mathrm{L})$ treatment plus high glucose $(\mathrm{HG}+$ Met). Data was compared among cells at each timepoint. ${ }^{*} P<0.05$, HG $(16.7 \mathrm{mmol} / \mathrm{L})$ versus ctrl and NG $(5.5 \mathrm{mmol} / \mathrm{L}) .{ }^{* *} P<0.05$, HG + Met versus HG $(16.7 \mathrm{mmol} / \mathrm{L}) .{ }^{\#} P<0.05, \mathrm{HG}+$ Met versus Ctrl and NG (5.5 mmol/L).

previously. The data revealed that the expressions of OCN (Figure 2(d)) and OPG (Figure 2(e)) were suppressed when cultured with high glucose level of $16.7 \mathrm{mmol} / \mathrm{L}$ than those with normal glucose level of $5.5 \mathrm{mmol} / \mathrm{L}$ and control medium $(P<0.05)$, while those of MMP1 (Figure 2(a)), MMP2 (Figure 2(b)), Coll $\alpha$ (Figure 2(c)), or RANKL (Figure 2(f)) were not affected by high glucose. In addition, MMP1 and MMP2 mRNA and protein production were significantly suppressed by $300 \mu \mathrm{mol} / \mathrm{L}$ metformin ( $\mathrm{HG}+$ Met), not by the change of glucose level alone. It is interesting that metformin promoted the expression of OCN to the extent that is even higher than the cells cultured in normal glucose medium (Figure 2(d)). Metformin also suppressed the expression of MMP1 (decreased by 0.74 -fold) and MMP2 (decreased by 0.62 -fold).

(3) To evaluate the function of the osteoblast, MG63 osteoblast-like cells were inducted with osteogenic mediums for 6, 12, and 18 days. Alkaline phosphatase (ALP) in these cells was detected with an automatic biochemical analyzer. As shown in Figure 3, when exposed to high glucose for 6 days, 12 days, and 18 days, MG63 cells have lower ALP activity compared with those exposed to normal glucose. In comparison, metformin could attenuate the downregulation completely at day 6 , partly at day 12 , but not at day 18 .

\section{Discussion}

It is well-accepted that diabetes mellitus (DM) could increase the risk of osteoporosis and fragility fractures $[2,3]$. As the most commonly used oral antidiabetic drug, metformin was reported to be protective against bone loss [5]. As we know, osteoblast proliferation is the key element affecting bone health [12], so it is necessary to research on the influences from high glucose and metformin. In this study, CCK8 assay at day 3 and day 7 revealed that high glucose could suppress the proliferation of osteoblasts, while metformin could attenuate this effect. In addition, the protection of metformin seems independent of the glucose level. The mechanisms of how high glucose disturbs the proliferation and how metformin corrects it could be very complicated and have not yet been elucidated completely. Reactive oxygen species (ROS) system, apoptosis, AMP-activated protein kinase (AMPK), and osteogenic genes are all reported to perform somehow in these procedures $[13,14]$.

Matrix metalloproteinases (MMPs) are able to degenerate type I collagen, activating bone absorption [10]. Some of the matrix metalloproteinases can augment the expression of the osteogenic genes such as osterix, type 1 collagen, alkaline phosphatase, and osteocalcin [15]. There are few reports about how metformin affects matrix metalloproteinases in osteoblast under high glucose. In our result, mRNA and protein levels of Col $\alpha, \mathrm{MMP} 1$, and MMP2 were affected by metformin rather than glucose concentration. And Coll $\alpha$ seemed to be controlled by metformin at the gene transcription level, aside from the well-known enzyme-substrate level.

It was reported that high glucose $(30 \mathrm{mmol} / \mathrm{L})$ increases the expression of MMP2 [16]; and MMP1 expression in peripheral blood was found to be elevated in chronic diabetic patients [17]. However, the elevation of MMP1/2 was not observed in our experiment. The difference may be explained by the relatively moderate glucose level $(16.7 \mathrm{mmol} / \mathrm{L})$ and short term of treatment in our experiment. At least in the experiment conditions of our study, aside from those osteogenic genes, MMPs were affected by metformin rather than the glucose level. Whether metformin attenuates the suppression of proliferation through MMPs remains to be determined. 
ALP has been widely recognized as one of the most important early marker for osteoblast differentiation [18]. So in this study, ALP activity was used as the indicator of osteoblast differentiation and maturation. Our result showed that high glucose could significantly suppress ALP activity at days 6,12 , and 18 , while metformin could rescue them completely at day 6 , partly at day 12 , but not at day 18 . This result implied that the metformin functioned mainly at earlier stage and not in later stage. One of the possible explanations for this interesting phenomenon might be that the osteoblasts on their early stage of differentiation could be more sensitive to chemical stimulations. More work should be done to confirm it in the future.

OPG and RANKL are two important factors produced by osteoblasts, affecting the activation of osteoclasts, so as to function on the protection or absorption of the bone tissues, respectively [19]. So the ratio of OPG/RANKL could be one mark for the balance of the bones [20]. High glucose, some hormones, and lots of chemical compounds are believed to influence the osteoblasts through the OPG/RANKL/RANK system [21-23]. In our studies, high glucose $(16.7 \mathrm{mmol} / \mathrm{L})$ and metformin $(300 \mu \mathrm{mol} / \mathrm{L})$ mainly affected the expression of OPG rather than RANKL. In this study, we did experiments on the glucose level of $16.7 \mathrm{mmol} / \mathrm{L}$, which is a relatively moderate glucose level. Future studies with much higher glucose levels might have different results. At least our study indicated that a not-so-high glucose level was already enough to cause a decrease on the ratio of OPG/RANKL, and metformin was a cure to correct it.

\section{Conclusion}

Metformin, a former antidiabetic drug, can protect the MG63 osteoblast-like cells from the harm of high glucose, which not only inhibited the proliferation of the osteoblasts but also decreased the expression of osteogenic genes, for example, Coll $\alpha$, OCN, and OPG. Metformin can inhibit the expression of MMP1 and MMP2, while promoting the expression of Coll $\alpha$, OPG, and OCN. The most possible time course of metformin influencing the osteoblasts is on the early stage of cell proliferation.

\section{Conflict of Interests}

The authors declare that there is no conflict of interests regarding the publication of this paper.

\section{Authors' Contribution}

Xinyu Shao and Xiaojun Cao contributed equally to this paper.

\section{Acknowledgments}

This study was supported in part by research Grants from Suzhou Society Development (Grants SS201022, SS201219, and SYSD201380) and Science \& Technology Support Program (SS201246).

\section{References}

[1] K. Wongdee and N. Charoenphandhu, "Osteoporosis in diabetes mellitus: possible cellular and molecular mechanisms," World Journal of Diabetes, vol. 2, no. 3, pp. 41-48, 2011.

[2] N. P. Botushanov and M. M. Orbetzova, "Bone mineral density and fracture risk in patients with type 1 and type 2 diabetes mellitus," Folia Medica, vol. 51, no. 4, pp. 12-17, 2009.

[3] M. Janghorbani, R. M. van Dam, W. C. Willett, and F. B. Hu, "Systematic review of type 1 and type 2 diabetes mellitus and risk of fracture," The American Journal of Epidemiology, vol. 166, no. 5, pp. 495-505, 2007.

[4] R. K. Campbell and J. R. White Jr., "More choices than ever before: emerging therapies for type 2 diabetes," The Diabetes Educator, vol. 34, no. 3, pp. 518-534, 2008.

[5] C. Wang, H. Li, S. G. Chen et al., "The skeletal effects of thiazolidinedione and metformin on insulin-resistant mice," Journal of Bone and Mineral Metabolism, vol. 30, no. 6, pp. 630-637, 2012.

[6] S. Dacic, I. Kalajzic, D. Visnjic, A. C. Lichtler, and D. W. Rowe, "Collal-driven transgenic markers of osteoblast lineage progression," Journal of Bone and Mineral Research, vol. 16, no. 7, pp. 1228-1236, 2001.

[7] Y. Cao, X. Liu, and H. Xu, "Utility of serum tartrate-resistant acid phosphatase isoform $5 \mathrm{~b}$, bone alkaline phosphatase and osteocalcin in osteoporotic fractures in Chinese patients," Clinical Laboratory, vol. 58, no. 7-8, pp. 845-850, 2012.

[8] M. S. Stalvey, K. L. Clines, V. Havasi et al., "Osteoblast CFTR inactivation reduces differentiation and osteoprotegerin expression in a mouse model of cystic fibrosis-related bone disease," PLoS ONE, vol. 8, no. 11, Article ID e80098, 2013.

[9] S. Y. Lee, K. S. Lee, S. H. Yi, S. H. Kook, and J. C. Lee, "Acteoside suppresses RANKL-mediated osteoclastogenesis by inhibiting c-Fos induction and NF- $\kappa$ B pathway and attenuating ROS production," PLoS ONE, vol. 8, no. 12, Article ID e80873, 2013.

[10] L. S. Holliday, H. G. Welgus, C. J. Fliszar, G. M. Veith, J. J. Jeffrey, and S. L. Gluck, "Initiation of osteoclast bone resorption by interstitial collagenase," The Journal of Biological Chemistry, vol. 272, no. 35, pp. 22053-22058, 1997.

[11] Y. Tao, M. L. Zhang, P. C. Ma et al., "Triptolide inhibits proliferation and induces apoptosis of human melanoma A375 cells," Asian Pacific Journal of Cancer Prevention, vol. 13, no. 4, pp. 16111615, 2012.

[12] H. Sun, K. Dai, T. Tang, and X. Zhang, "Regulation of osteoblast differentiation by slit2 in osteoblastic cells," Cells Tissues Organs, vol. 190, no. 2, pp. 69-80, 2009.

[13] D. Zhen, Y. Chen, and X. Tang, "Metformin reverses the deleterious effects of high glucose on osteoblast function," Journal of Diabetes and its Complications, vol. 24, no. 5, pp. 334344, 2010.

[14] Y. S. Lee, Y. S. Kim, S. Y. Lee et al., "AMP kinase acts as a negative regulator of RANKL in the differentiation of osteoclasts," Bone, vol. 47, no. 5, pp. 926-937, 2010.

[15] L. Mao, M. Yano, N. Kawao, Y. Tamura, K. Okada, and H. Kaji, "Role of matrix metalloproteinase-10 in the BMP-2 inducing osteoblastic differentiation," Endocrine Journal, vol. 60, no. 12, pp. 1309-1319, 2013.

[16] J. Yang, Q. Zhou, Y. Wang, K. Liu, and J. Zhang, "Effect of high glucose on PKC and MMPs/TIMPs in human mesangial cells," Zhong Nan Da Xue Xue Bao Yi Xue Ban, vol. 34, no. 5, pp. 425431, 2009 (Chinese). 
[17] N. Stoynev, I. Dimova, B. Rukova et al., "Gene expression in peripheral blood of patients with hypertension and patients with type 2 diabetes," Journal of Cardiovascular Medicine, 2013.

[18] J. Feng, Z. Shi, and Z. Ye, "Effects of metabolites of the lignans enterolactone and enterodiol on osteoblastic differentiation of MG-63 cells," Biological and Pharmaceutical Bulletin, vol. 31, no. 6, pp. 1067-1070, 2008.

[19] L. Tan, Y. Ren, J. Wang et al., "Osteoprotegerin and ligand of receptor activator of nuclear factor," Angle Orthodontist, vol. 79, no. 2, pp. 292-298, 2008.

[20] K. Park, W. C. Ju, J. H. Yeo et al., "Increased OPG/RANKL ratio in the conditioned medium of soybean-treated osteoblasts suppresses RANKL-induced osteoclast differentiation," International Journal of Molecular Medicine, vol. 33, no. 1, pp. 178184, 2014.

[21] S. K. Mok, W. F. Chen, W. P. Lai et al., "Icariin protects against bone loss induced by oestrogen deficiency and activates oestrogen receptor-dependent osteoblastic functions in UMR 106 cells," The British Journal of Pharmacology, vol. 159, no. 4, pp. 939-949, 2010.

[22] A. García-Hernández, H. Arzate, I. Gil-Chavarría, R. Rojo, and L. Moreno-Fierros, "High glucose concentrations alter the biomineralization process in human osteoblastic cells," Bone, vol. 50, no. 1, pp. 276-288, 2012.

[23] K. B. Maresova, K. Pavelka, and J. J. Stepan, "Acute effects of glucocorticoids on serum markers of osteoclasts, osteoblasts, and osteocytes," Calcified Tissue International, vol. 92, no. 4, pp. 354-361, 2013. 


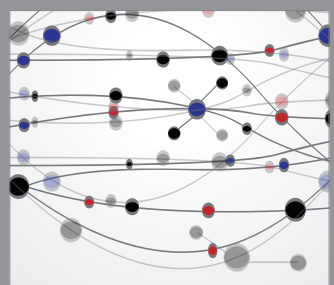

The Scientific World Journal
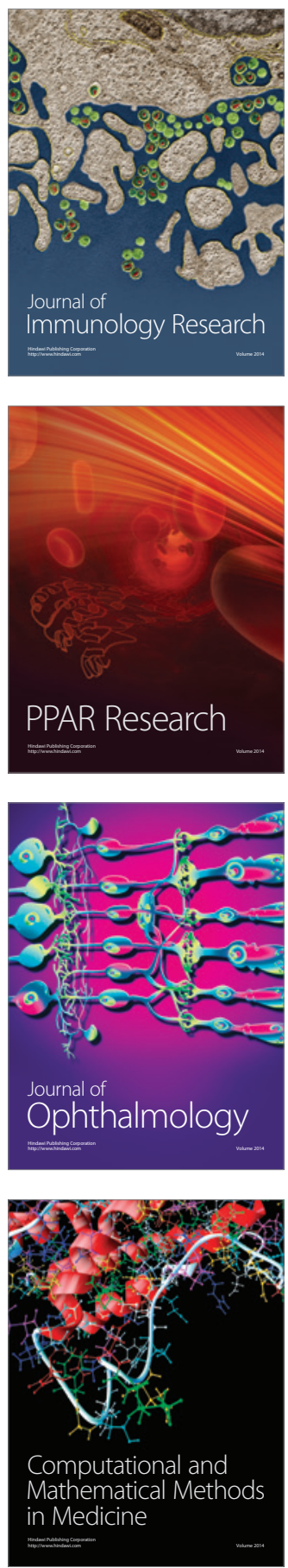

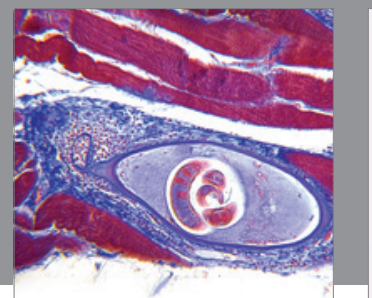

Gastroenterology

Research and Practice
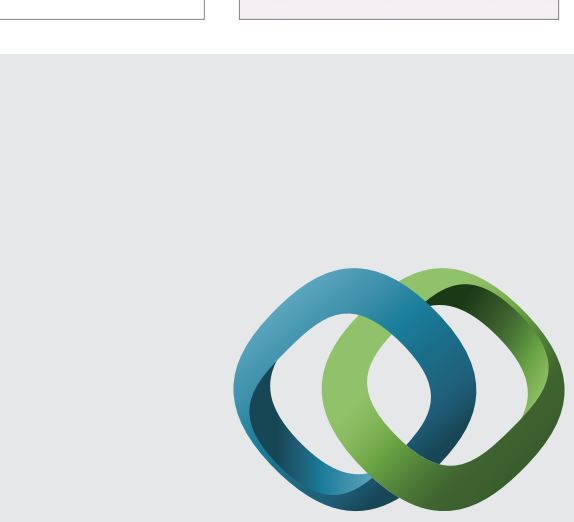

\section{Hindawi}

Submit your manuscripts at

http://www.hindawi.com
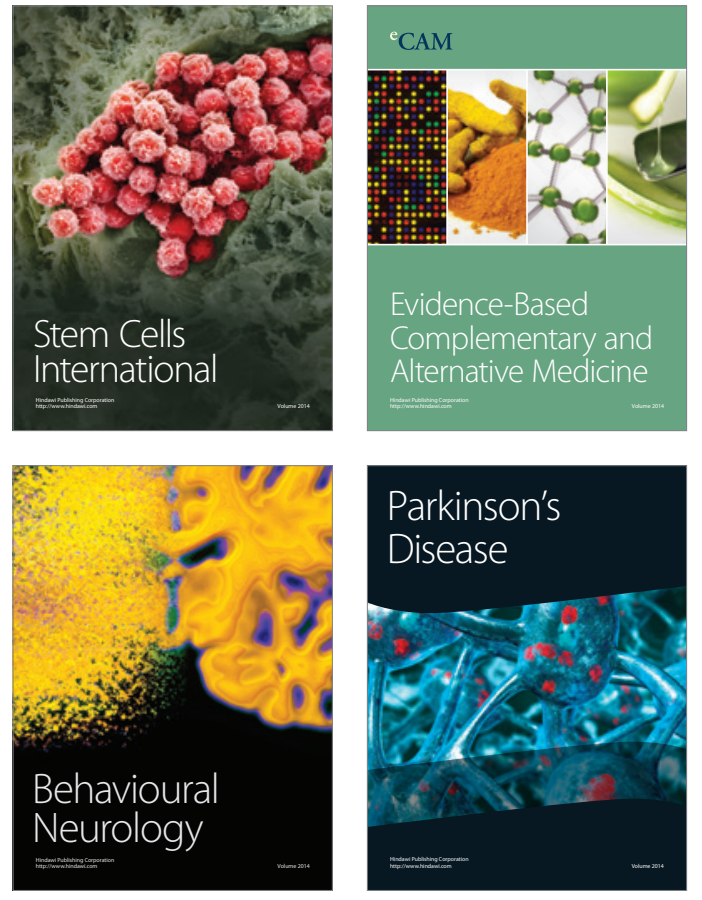
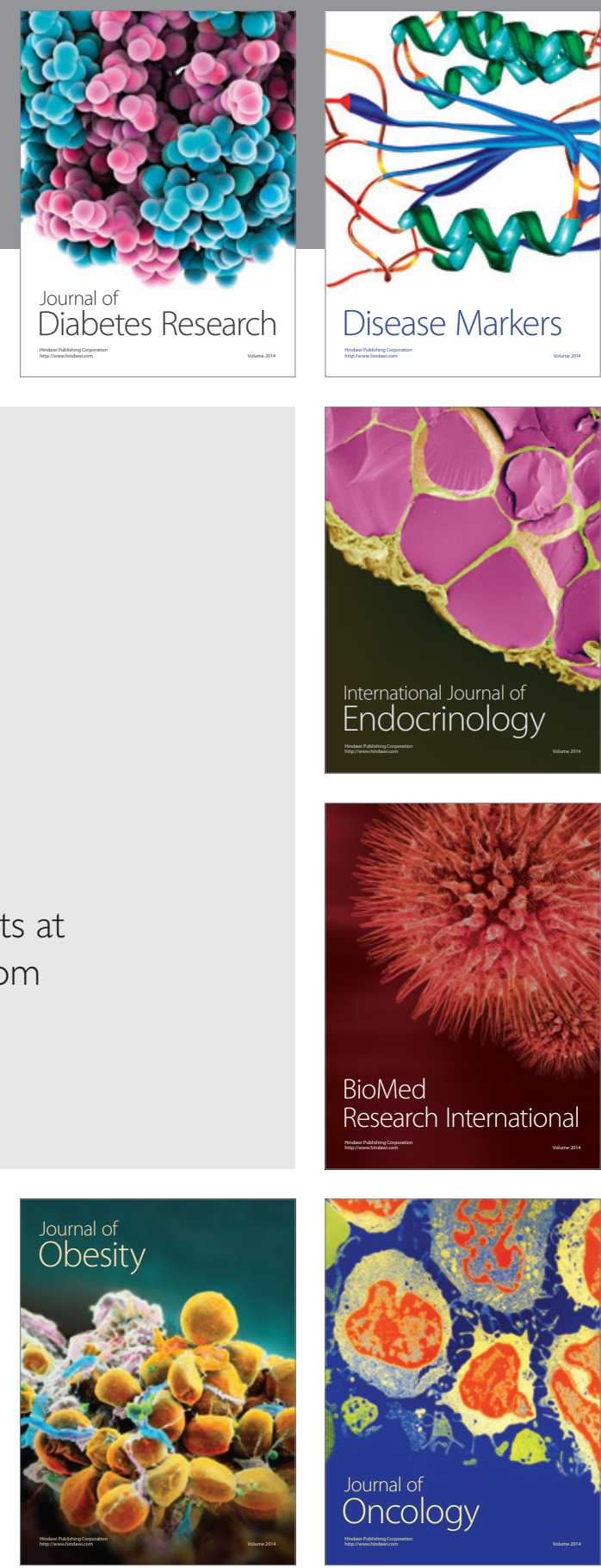

Disease Markers
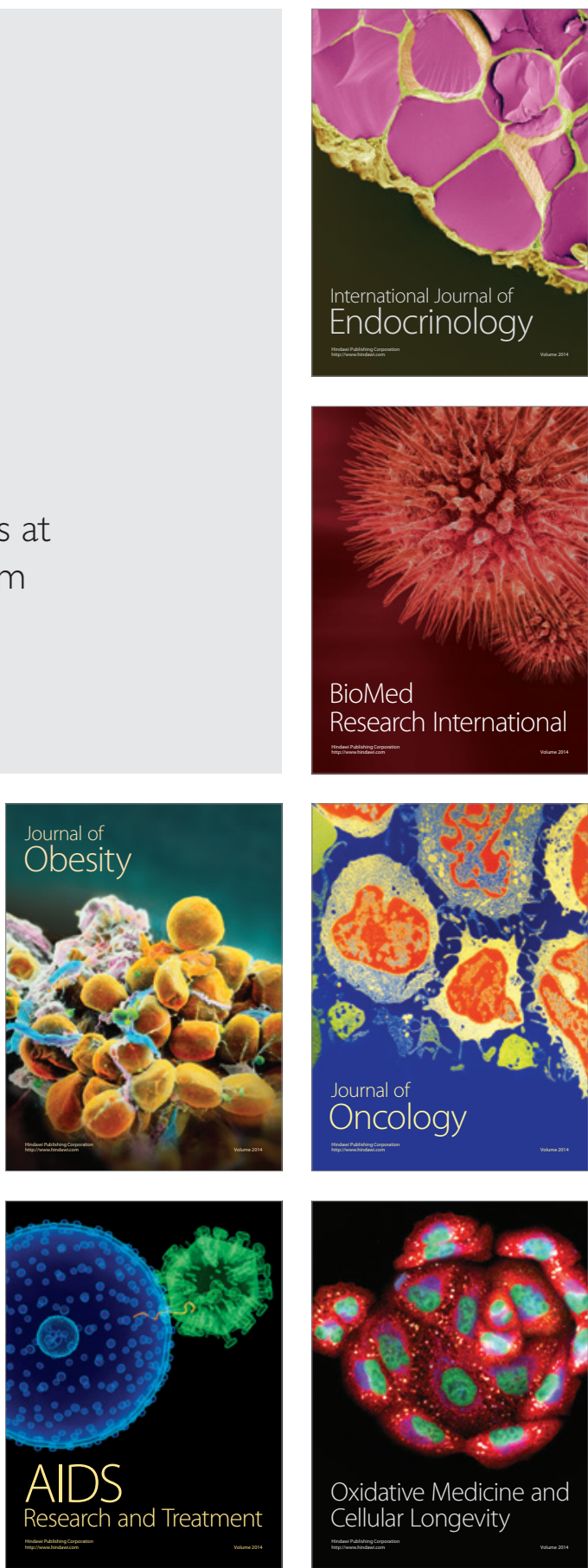